\title{
Fake news sobre drogas: pós-verdade e desinformação
}

\section{Fake news on drugs: post-truth and misinformation}

\section{Heitor Pasquim ${ }^{\mathrm{a}}$}

(1) https://orcid.org/0000-0002-4994-7399

E-mail: hpasquimळgmail.com

\section{Marcos Oliveira ${ }^{b}$}

(1) https://orcid.org/0000-0002-1000-2902

E-mail: marcosflavioifg®gmail.com

\section{Cássia Baldini Soares ${ }^{c}$}

(D) https://orcid.org/0000-0002-8457-3775

E-mail: cassiaso®usp.br

aUniversidade Federal de Goiás. Faculdade de Educação Física e Dança. Goiânia, GO, Brasil.

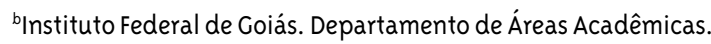
Aparecida de Goiânia, GO, Brasil.

'Universidade de São Paulo. Escola de Enfermagem. Departamento de Enfermagem em Saúde Coletiva. São Paulo, SP, Brasil.

\section{Correspondência}

\section{Resumo}

O objetivo deste artigo é analisar os discursos sobre drogas em publicações da internet cujo conteúdo foi identificado como falso em plataformas de checagem de dados. Trata-se de estudo de abordagem qualitativa, que seguiu procedimentos de análise do discurso. A partir de pesquisa na internet, selecionaram-se 85 notícias falsas sobre drogas. A análise indica que o tom negativo e alarmista é o mais comum. O desfecho trágico mais citado foi a morte. Outros desfechos negativos também foram lembrados, como: assalto, transformar-se em zumbi, câncer, prostituição, infecções sexualmente transmissíveis e até mesmo canibalismo. Foram identificadas três unidades de discurso: sátira sobre drogas com potencial para enganar; drogado como categoria de acusação; e epidemia das drogas ilícitas. Como pano de fundo da problematização acerca do fenômeno fake news, questionam-se concepções que advogam a impossibilidade da compreensão do real, abrindo espaço para que o conhecimento acadêmico-científico seja equiparado a convicções pessoais, reforçando subjetivismos e irracionalismos que tendem a fortalecer a recepção e a proliferação de fake news nos mais variados campos do conhecimento.

Palavras-chave: Saúde Coletiva; Usuários de Drogas; Comunicação em Saúde; Pesquisa Qualitativa. 


\section{Introdução}

The aim of this article is to analyze the discourses about illicit drugs in internet publications whose content was identified as false in fact-checking platforms. This is a qualitative study based on discourse analysis procedures. From an internet search, 85 false news articles about drugs were selected. The analysis indicates that negative and alarmist approaches are the most common. The tragic outcome most frequently cited was death. Other negative outcomes were cited, such as: robberies, turning into a zombie, cancer, prostitution, sexually transmitted diseases, and even cannibalism. Three units of discourse were identified: satire about drugs with the potential to deceive; 'drughead' as a category of accusation; and an epidemic of illicit drug use. As a background to the problematization of the fake news phenomenon, we question conceptions that advocate the impossibility of understanding the real world and allow the academic/scientific knowledge to be equated with personal convictions, reinforcing irrational subjectivities that tend to strengthen the reception and spread of fake news in the most varied fields of knowledge.

Keywords: Collective Health; Drug Users; Communication in Health; Qualitative Research.
O fenômeno das fake news se popularizou nas eleições presidenciais norte-americanas. Esse neologismo, retomado nas eleições de 2016, foi eleito a "palavra de 2017" pelo dicionário britânico Collins ('Fake news'..., 2017).

O destaque crescente das fake news na mídia evidencia a necessidade de entendê-las. Allcott e Gentzkow (2017) definem fake news como notícias intencional e comprovadamente falsas, que poderiam induzir o leitor ao erro. Para Paula, Silva e Blanco (2018), as fake news relacionam-se ao tema da pós-verdade, que, por sua vez, foi eleito o termo do ano em 2016 pelo dicionário Oxford. A pós-verdade pode explicar o fenômeno em que fatos objetivos são dotados de menor poder de convencimento e de formação da opinião pública perante as crenças pessoais (Harsin, 2018).

Derakhshan e Wardle (2017) identificaram sete tipos de fake news: sátira ou paródia; falsa conexão; conteúdo enganoso; falso contexto; conteúdo impostor; conteúdo manipulado; conteúdo fabricado. Nesse sentido, nem toda notícia falsa cria um conteúdo novo, totalmente falso, o que dificulta checar a veracidade das informações.

A própria checagem de fatos não está imune a distorções. Afinal, a definição do que é verdade, mentira, informação imprecisa, exagerada ou insustentável também é atravessada por interesses e por convicções.

Algumas respostas institucionais têm se organizado contra as notícias falsas, por exemplo, a publicação de dicas para ajudar as pessoas a identificarem boatos virtuais, como o diagrama da International Federation of Library Associations and Institutions (IFLA, 2019), traduzido para 41 idiomas, assim como a formação de redes colaborativas de checagem de informações (fact-checking). Todavia, identificar e desmentir cada foto, vídeo e notícia parece uma tarefa hercúlea, mesmo se acompanhada por processo massivo de alfabetização digital.

Embora medidas de conscientização estejam recebendo destaque recentemente, as notícias falsas não são novas, pois boatos e embustes sempre estiveram presentes na mídia tradicional (Conde, 2018). 0 novo nas fake news é sua rápida 
disseminação e a relativa facilidade de acesso por amplas camadas da população, dado o poder de alcance das novas mídias.

O crescimento mundial e a influência direta das fake news na opinião pública e no comportamento cotidiano têm gerado preocupações em diversos setores da sociedade. O caso é tão sério que foi associado à queda nas taxas de cobertura vacinal em todo mundo (Jervelund, 2018), o que levou o Ministério da Saúde do Brasil a criar um canal próprio para combater as "fake news da saúde", em 2018.

O conteúdo das fake news que abordam direta ou indiretamente a saúde e as drogas pode variar muito, percorrendo um amplo espectro entre o sensacionalismo e o pânico social.

É interessante notar que, na área das drogas, a gênese do proibicionismo estadunidense também se baseou em divulgação de pesquisas e informações questionáveis, nas primeiras décadas do século XX (Hari, 2018). Por existir uma série de estigmas que cercam o consumo de drogas (Baratta, 1994), as notícias relacionadas a elas parecem especialmente suscetíveis à proliferação de informações falsas e preconceituosas.

O objetivo deste estudo é analisar os discursos sobre drogas em publicações da internet cujo conteúdo foi identificado como falso em plataformas de checagem de dados.

\section{Método}

Trata-se de estudo qualitativo que utilizou a análise crítica de discurso (Meurer, 2005), a qual vê uma ocorrência discursiva ao mesmo tempo como texto, como manifestação de discursos e como prática social.
Para Bakhtin (2011), a unidade do discurso é o enunciado, e não uma frase ou uma oração desconectada da totalidade social. Enquanto processo concreto, a comunicação compreende interlocutores ativos, que, inseridos na realidade, voltam-se para a resposta e os discursos do outro.

Portanto, partindo dos estudos de análise crítica de discurso, este artigo compreende as fake news como mediação da realidade. Isto é, elas expressam a intencionalidade dos sujeitos falantes e seu posicionamento social, porque estão carregadas de ideologia.

Investigaram-se notícias em duas agências de checagem de fatos, a $\varepsilon$-farsas.com e a Boatos.org. Ambas compilam e elucidam todo tipo de boatos e notícias falsas que circulam em redes sociais. São as maiores agências especializadas em checagem de fatos em atividade no país, se desconsiderarmos Apublica.org, que investiga exclusivamente a administração pública.

Para garantir o rigor científico desta pesquisa, realizaram-se buscas exaustivas. Procurou-se compor o corpus empírico com busca ampla das notícias nos referidos sites de checagem. Em dezembro de 2018 foi realizado o levantamento das notícias em cada plataforma, por meio das palavras: droga; maconha; álcool; cocaína; crack; cerveja; cigarro. As notícias foram selecionadas após leitura de título, subtítulo e texto integral. Excluíram-se do corpus aquelas que não abordavam o tema droga; que tratavam sobre vacinas e outros medicamentos utilizados com fins terapêuticos.

Inicialmente, buscaram-se apenas notícias utilizando o portal $\varepsilon$-farsas.com. Para facilitar a apresentação, cada uma delas foi numerada, acrescentando-se a letra "f".

\section{Tabela I - Artigos selecionados do portal E-farsas.com}

\begin{tabular}{ll}
$\#$ & Título do artigo \\
$f_{1}$ & Misturar cerveja com limão mata! \\
$f_{2}$ & Relato da falecida ex-Paquita Patrícia do programa da XUXA! \\
$f_{3}$ & Vídeo de animais bêbados com marula é verdadeiro? \\
$f_{4}$ & Aconteceu no Barra Shopping (droga Burundanga ou escopolamina) \\
\hline
\end{tabular}


Tabela I - Continuação

\#

f5

f6

f7

f8

fo

fio

fII

fi2

fi3

fI 4

fi5

fi6

fi7

fi8

fig

f20

f2I

f22

f23

f 24

f25

f26

f27

f 28

f29

f3o

f3I

f32

f33

f34

f35

f36

f37

f38

\section{Título do artigo}

SPTV faz matéria com estudantes brisados! Será?

Ator Gary Dourdan do seriado CSI consumido pelas drogas!

É verdade que a maconha ajuda a curar o ebola?

37 morreram de overdose no Colorado após legalização da maconha!

Brasileiro executado na Indonésia ganha estátua no Rio de Janeiro!

Pílula faz gari virar técnico da Receita Federal! Será?

Neymar é flagrado fumando maconha! Será verdade?

A Souza Cruz vai lançar o cigarro de maconha Marley?

Neurofos: 0 golpe da pílula que te deixa mais inteligente!

Arlindo Cruz é preso com cocaína no Rio de Janeiro!

Festinha regada a drogas com atores da Globo! Será?

Jovens incendeiam carro após acenderem lança perfume!

Nova droga "Docinho" está se espalhando pelas escolas?

Adriano Imperador virou mendigo na favela por causa das drogas?

A NASA vai pagar 70 mil pra voluntários fumarem maconha?

Estudo revelou que miojo é pior pra saúde do que maconha?

Russo bebeu demais, ressuscitou no necrotério e voltou pro bar?

Senador com saquinho de cocaína durante impeachment de Dilma?

Consumo da bebida Skol Beats causa câncer?

Droga que mata em 3 dias chegou no Brasil?

Nova droga é usada nos olhos e mata de overdose! Será verdade?

Mineiro coloca boca de fumo à venda! Será verdade?

Alcoólatra morre após beber água pensando que era cachaça! Será verdade?

O Burger King vai imprimir notas no papel de seda durante a Marcha da Maconha?

Um casal gay foi flagrado ensinando o filho adotivo a fumar e a beber?

A Polícia capturou uma mulher zumbi sob efeitos da droga Cloud Nine?

Pirulito Energy contém energético e quase causou a morte de crianças?

Marielle Franco foi esposa do Marcinho VP? Era do Comando Vermelho?

Imagens mostram médica antes e depois do vício no crack! Será verdade?

Um menino ficou com a boca cheia de feridas após consumir a nova droga Morango Rápido?

Cogumelos alucinógenos causaram distúrbio grave em uma pizzaria?

Gustavo Perrella, do helicóptero com cocaína, foi nomeado para o Ministério do Esporte de Bolsonaro?

Dois coroinhas foram presos por colocar maconha no incensário da igreja?

Propaganda antiga dos cigarros Winston falava sobre benefícios para as grávidas? 
Após essa primeira seleção, foi iniciado outro Boatos.org, as quais também foram numeradas, levantamento de notícias, a partir da plataforma acrescentando-se a letra "b".

\section{Tabela 2 - Artigos selecionados do portal Boatos.org}

\begin{tabular}{|c|c|}
\hline \# & Título do artigo \\
\hline bı & Boato aponta que Aécio Neves seria usuário de cocaína \\
\hline b2 & Hoax - Ex-paquita Patrícia morre aos 17 anos de aids após se envolver com drogas \\
\hline$b_{3}$ & Notícia falsa: overdose de maconha matou 37 pessoas no Colorado \\
\hline$b_{4}$ & Boato aponta que Monsanto quer plantar maconha transgênica no Uruguai \\
\hline$b_{5}$ & Balela: maconha pode ser liberada para plantio no Brasil em 2014 \\
\hline b6 & Notícia de que Marlboro vai lançar cigarro de maconha é falsa \\
\hline b7 & Pegadinha: Aplicativo LIVR só pode ser acessado por bêbados \\
\hline b8 & Mentira: Dilma diz que consumo de cocaína mostra crescimento econômico \\
\hline b9 & Lenda: Branca de Neve e os Sete Anões leva mensagem sobre cocaína \\
\hline bıo & História falsa: PSDB quer processar Heineken por usar estrela vermelha \\
\hline bıl & Foto falsa: Gary Dourdan, ator de CSI, perde a luta contra o crack \\
\hline$b_{12}$ & Boato: Aécio Neves concede entrevista bêbado ao Estadão \\
\hline bi3 & Lenda: Lucy in The Sky With Diamonds é a canção do LSD \\
\hline $\mathrm{bl}_{4}$ & Balela: fumar maconha pode ajudar na cura do vírus ebola \\
\hline bi5 & Colocar limão no copo de cerveja é fatal \\
\hline bı6 & Bandidos usam droga burundanga (escopolamina) para assaltos \\
\hline bı17 & Projeto de legalização da maconha de Jean Wyllys é arquivado, diz hoax \\
\hline bı 8 & Usuários de drogas podem ter $10 \%$ de vagas em concurso, diz informação falsa \\
\hline big & Arlindo Cruz é preso por porte de cocaína, afirma boato \\
\hline b2o & NASA encontra planeta coberto de maconha \\
\hline b21 & Fumar narguilé é como fumar 100 cigarros? \\
\hline b22 & Festa de fim de ano da Globo tem Tonico Pereira, drogas e prostitutas, diz boato \\
\hline b23 & Adolescentes usam absorventes para ficarem bêbados \\
\hline b24 & 50 Cent emagreceu após fumar maconha \\
\hline b25 & Cigarro faz fumaça colorida como um arco-íris \\
\hline b26 & Docinho: nova droga está chegando às escolas \\
\hline b27 & Cloud nine, droga que causa canibalismo, chega ao Brasil \\
\hline b28 & Senador é flagrado com cocaína em sessão do impeachment \\
\hline b29 & Ivete Sangalo é flagrada cheirando cocaína em vídeo \\
\hline b30 & Lei Seca será revogada! É o fim do bafômetro \\
\hline b31 & Adriano Imperador, viciado em drogas, virou mendigo na praia \\
\hline$b_{32}$ & Beber vinagre altera resultado do teste do bafômetro \\
\hline
\end{tabular}




\section{Tabela 2 - Continuação}

\begin{tabular}{|c|c|}
\hline \# & Título do artigo \\
\hline b33 & Filho de casal gay bebe cerveja e fuma cigarro em vídeo \\
\hline b34 & Filho de Bonner e Fátima dirigia bêbado e sem habilitação \\
\hline b35 & Droga que mata em três dias chega ao Brasil \\
\hline$b_{36}$ & Chaveiro cachimbo colorido é a nova moda para consumo de drogas \\
\hline$b_{37}$ & Estão oferecendo papel com droga para cheirar no Walmart \\
\hline b38 & Budweiser falsificada é fabricada por chineses e vendida no Brasil \\
\hline b39 & Fábrica clandestina de Heineken falsificada é descoberta \\
\hline$b_{40}$ & Dr. Paulo Ubiratan dá entrevista sobre saúde a TV de Porto Alegre \\
\hline$b_{41}$ & Droga Manga Rosa chegou ao Brasil, parece açúcar e é mortal \\
\hline$b_{42}$ & Nova droga DOFE é usada nos olhos e vendida nas raves \\
\hline$b_{43}$ & Burger King vai imprimir nota fiscal em seda para Marcha da Maconha \\
\hline b44 & Pílula zumbi chegou ao Brasil: vídeo mostra efeito da droga em mulher \\
\hline$b_{45}$ & Primo de Marcelo Freixo, Gustavo, deu drogas e estuprou alunos \\
\hline$b_{4} 6$ & Caminhão do deputado Romanelli foi apreendido com drogas \\
\hline b47 & Dirigir alcoolizado é crime com pena de 5 a 8 anos de prisão, diz Lei 13.546 \\
\hline$b_{48}$ & Não beba Skol! Marca de cerveja está contaminada e causando doenças \\
\hline b49 & Nova droga Strawberry Quick está sendo distribuída em escolas \\
\hline$b_{50}$ & Rússia libera uso de maconha e cocaína em estádios na Copa do Mundo \\
\hline$b_{51}$ & Governo está pagando Bolsa Crack de R\$ 1.500 para todos os viciados \\
\hline b52 & Droga e armas são achadas em acampamento dos Sem Terra em Descalvado \\
\hline$b_{53}$ & Balas de ursinho com droga levam crianças ao óbito no Brasil \\
\hline$b_{54}$ & Lula teve crise de abstinência de álcool na sede da PF e quase morreu \\
\hline$b_{55}$ & Cerveja Heineken patrocina briga de cães em rinha na Mongólia \\
\hline$b_{5} 6$ & Bruno Maranhão do MST foi preso em flagrante com armas e drogas \\
\hline$b_{57}$ & Governo paga Bolsa Usuário de $\mathrm{R} \$ 1.000$ pelo resto da vida para drogados \\
\hline$b_{5} 8$ & Atestado médico para quem estiver com ressaca é aprovado por conselho \\
\hline$b_{59}$ & Bolsonaro é flagrado com camisa do PT e cigarro de maconha em foto \\
\hline b6o & Propaganda do cigarro Winston recomenda que mulher fume durante a gravidez \\
\hline b61 & João Amoêdo diz que é a favor do aborto e da descriminalização das drogas \\
\hline b62 & Vídeo mostra goleiro Alisson, da seleção, com três mulheres e usando cocaína \\
\hline b63 & Nova droga chamada Morango Rápido está sendo distribuída nas escolas \\
\hline b64 & Cerveja puro malte gelada mata células cancerígenas e cura câncer \\
\hline b65 & Gustavo Perrella é nomeado como ministro do Esporte de Bolsonaro \\
\hline b66 & Paulo Guedes diz que não dará dinheiro para Carnaval, Parada Gay e marchas \\
\hline b67 & Médica usuária de crack é filmada vivendo nas ruas \\
\hline
\end{tabular}


Selecionaram-se 105 artigos que abordavam o tema droga, sendo 38 do portal $\varepsilon$-farsas.com e 67 do Boatos.org. Depois de ler todos os artigos, 20 conteúdos semelhantes checados foram identificados pelos dois portais. Esses não foram excluídos da análise, porque apresentam comentários, versões ou datas não idênticas, mas serão agrupados, acrescentando-se o símbolo “ ”, para facilitar a sua identificação quando a análise fizer referência a fake news e não ao artigo de checagem. São eles: f1 b15; f2 b2; f6 b11; f7 b14; f8 b3; f14 b19; f15 b22; f17 $\mathrm{b}_{2} 6$; f18 $\mathrm{b}_{31} ; \mathrm{f}_{22} \sim \mathrm{b}_{2} 8$;

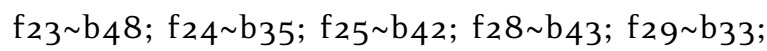
f3o b44; f33 b67; f34 b63; f36 b65; f38 b6o. Subtraindo o número de notícias semelhantes do total, tem-se 85 fake news sobre drogas.

Após selecionar essas notícias, decidiu-se, por conveniência, utilizar apenas os dois portais de checagem. Nesse momento, todas as notícias foram relidas cuidadosamente. A leitura foi guiada por instrumento de extração de dados, que, por sua vez, estava organizado em: informações sobre o ano de publicação do artigo de checagem; a droga citada; desfechos do uso de drogas; alvos da informação falsa; estratégias de ação/ prevenção; classificação da notícia; e trechos salientes.

Para expor os dados da pesquisa foram elencadas categorias a posteriori, analisadas à luz da perspectiva da saúde coletiva, que compreende a demanda e a oferta de drogas como inerentes ao processo histórico-social e, portanto, à determinação social que envolve indivíduos, famílias e classes nas suas diferentes possibilidades de reprodução social (Santos; Soares, 2013; Soares, 2007).

\section{Resultados}

Os artigos de checagem de fatos selecionados acusam as fake news de serem: boato; rumor; balela; história falsa; informação falsa; foto falsa; pegadinha; mentira; lenda; lorota; e hoax. Alguns reportam mais de uma versão da mesma notícia falsa. Isso evidencia a dificuldade de lidar com um fenômeno dinâmico, capaz de produzir notícias em mutação que se adaptam frequentemente para parecerem críveis.

Para classificar as fake news, jornalistas ligados às agências apresentam o conteúdo investigado, buscam comparar a fonte original com outras, apoiando-se em referências oficiais e especialistas. Todavia, a maior parte das notícias não conta com uma fonte ou origem de fácil verificação. Aparentemente, em muitos casos a fonte e o meio de comunicação que compartilha a informação falsa se confundem. Neste caso, o canal de comunicação legitima o fato sem fonte. Não raro os meios de comunicação assumidamente jocosos (nacionais e internacionais) foram utilizados como fonte para as notícias falsas, por exemplo, Blog Joselito Muller, G17, MTVV-Maconha Torna Você Violento, Diário Pernambucano, Sacizento, Olé do Brasil, The Daily Currant, Jornal VDD, entre outros.

O Gráfico 1 evidencia um pico de fake news sobre drogas em 2014 e uma tendência de crescimento até 2018.

\section{Gráfico I- Número de fake news sobre drogas por ano de publicação}

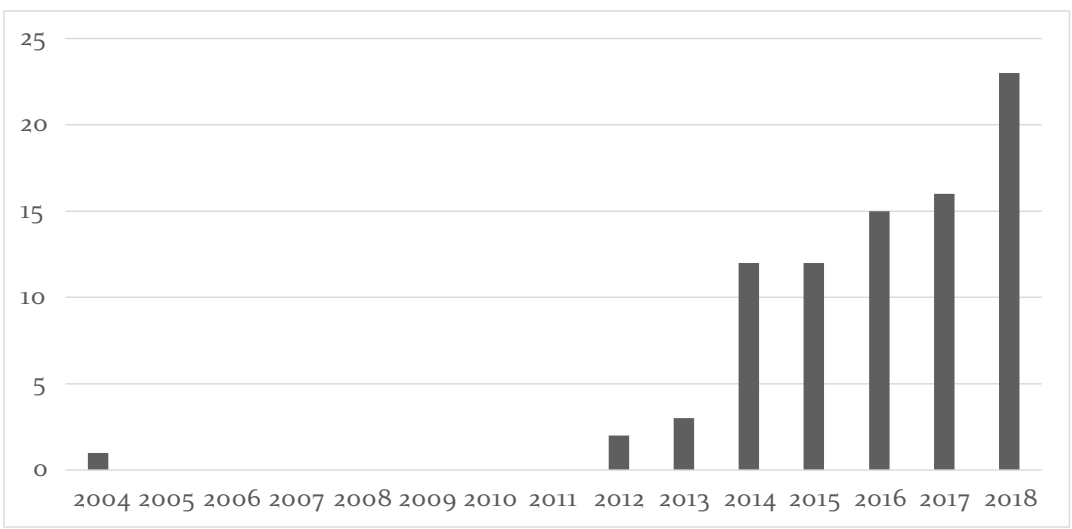


O ano de 2014 foi repleto de acontecimentos marcantes para os brasileiros. No campo das drogas, realizou-se a Marcha da Maconha de São Paulo, que reuniu milhares de pessoas (Marcha da maconha..., 2014), e tramitava na Câmara dos Deputados o Projeto de Lei $n^{0} 7.187 / 2014$, propondo a regulamentação do controle, da plantação, do cultivo, da colheita, da produção, da aquisição, do armazenamento, da comercialização e da distribuição de maconha e seus derivados. Esse contexto gerou discussões e conflitos públicos que podem ter influenciado a produção e proliferação de fake news.

O Gráfico 2 quantifica as drogas nas fake news selecionadas, excluindo aquelas referentes à mesma notícia falsa nos dois portais. Vale ressaltar que nem todas especificam uma droga.

\section{Gráfico 2 - Citações das drogas por ano}

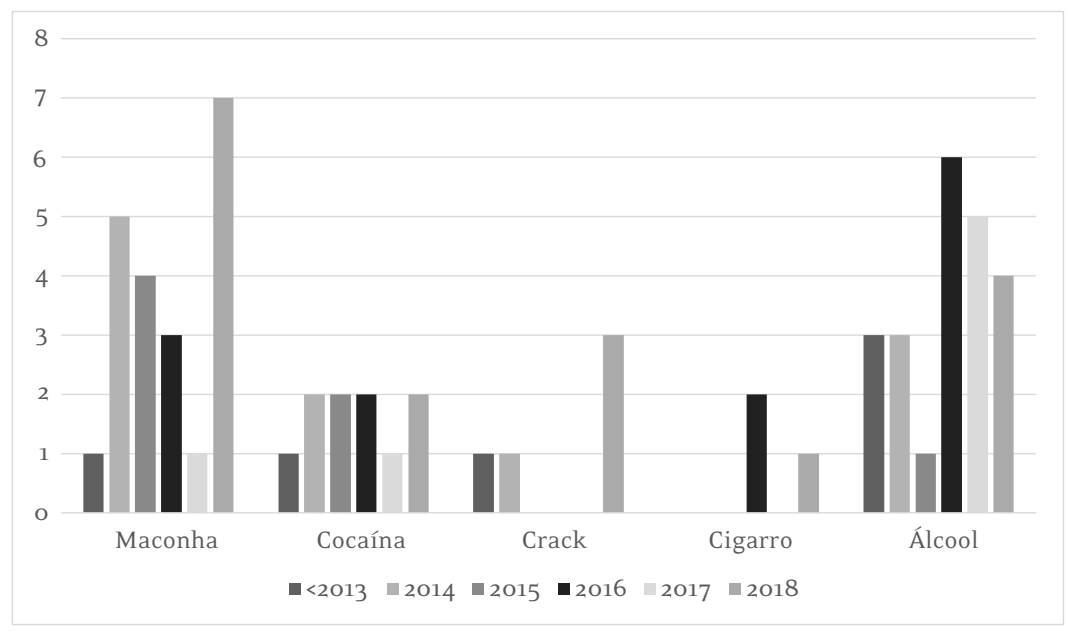

A droga mais frequente, com 22 citações, é uma substância lícita: o álcool. As drogas ilícitas mais citadas foram a maconha e a cocaína, com 21 e 11 citações respectivamente. Chama atenção a baixa quantidade de fake news sobre crack (5) e cigarro (3).

Segundo as notícias falsas, 9 novas drogas teriam chegado ao país, são elas: Focus X (f1o), Neurofos (f13), Docinho (f17, b26), Cloud Nine (f3o, b44, b27), Manga Rosa (b41), Dofe (f25, b42), Strawberry Quick ou Morango Rápido (b49, f34, b63), Burundanga (f4, b16) e Krokodyl (f24, b35). Segundo os próprios portais de checagem, algumas dessas drogas de fato existem (por exemplo, Krokodyl e Burundanga), mas elas são raras, e os relatos a respeito possuem informações inverídicas, o que coincide com dados apresentados pelo III Levantamento Nacional sobre o Uso de Drogas pela População Brasileira (Bastos, 2017).

O tom negativo e alarmista é o mais comum. 0 desfecho trágico mais citado foi a morte ( $\mathrm{f}_{1}, \mathrm{~b}_{15}$, $f_{2}, b_{2}, f_{8}, b_{3}, f_{24}, b_{34}, f_{25}, b_{41}, f_{27}, f_{31}, b_{40}, b_{53}$ ). Outros desfechos negativos também foram lembrados, como: assalto ( $\left.f_{4}, b_{16} 6, b_{3} 6\right)$; transformar-se em zumbi (f3o, b44); câncer (f23, b48); prostituição (f2, b2); infecções sexualmente transmissíveis ( $\mathrm{f}_{2}, \mathrm{~b} 2, \mathrm{~b} 23$ ); e canibalismo (b27).

Em menor quantidade, algumas notícias falsas relataram desfechos "positivos" para os usuários de droga, como: vaga em concurso (b18); bolsa crack (b51, b57); aumento da inteligência (f10, f13); cura do ebola ( $\left.f_{7}, b_{14}\right)$; benefícios do consumo para mulheres grávidas (f38, b59); e cura do câncer (b64).

Cinco notícias desmascaradas abordam mudanças nas políticas públicas de drogas: b5 aponta que o plantio de maconha poderia ser liberado em 2014; segundo b17, o projeto de legalização da maconha foi arquivado em 2015; já b3o diz que a Lei Seca será revogada porque gera mais acidentes no trânsito; b61 afirma que um candidato a presidente do Brasil defenderia a descriminalização das drogas; por fim, a notícia b47 alega que a lei tinha ficado ainda mais rígida para quem fosse pego dirigindo após beber. Essas notícias reportam desinformações, e algumas parecem parte 
de uma estratégia conservadora para descrédito de políticos e de governos.

Outras informações pragmáticas poderiam ser dicas de redução de danos, se fossem verdade. Por exemplo, a fake new que ensina como fugir do bafômetro usando vinagre (b32), ou a que apresenta um novo cachimbo para consumo de drogas (b36), ou ainda o direito à atestado médico para quem estiver de ressaca (b58). Todavia, essas apresentam a informação em tom de denúncia ou ironia.

Nem sempre as agências de checagem apontam as redes sociais onde a fake new se originou ou viralizou. A rede social mais citada é o Facebook (4o vezes), seguido de sites e blogs (22 vezes) e do Whatsapp (21 vezes).

Algumas notícias relatam estratégias do mercado para atrair novos usuários, como cores e sabores ( $f_{17}$, b25, b26, f31, f34, b63, b41, b49, b53) ou novas formas de administração das drogas (f25, b42, b23, b36). Os vários relatos com advertências envolvendo jovens e crianças ( $f_{5}, f_{16}, f_{17}, b_{26}, f_{29}, b_{33}, f_{31}, f_{34}, b_{62}$, $\mathrm{f}_{37}, \mathrm{f}_{34}, \mathrm{~b}_{3}, \mathrm{~b}_{23}, \mathrm{~b} 45, \mathrm{~b} 49, \mathrm{~b} 53$ ) parecem contribuir para sustentar o discurso de risco contra indivíduos e grupos considerados vulneráveis.

Algumas fake news trazem proposta de ação em forma de pedidos para o leitor. Nesse sentido, sugerem que a mensagem (falsa) seja compartilhada em redes sociais $\left(f_{1}, b_{15}, f_{2}, b_{2}, f_{4}, b_{16}, f_{25}, b_{41}\right.$, $f_{29}, b_{32}, f_{31}, f_{34}, b_{62}, b_{29}, b_{36}, b_{46}, b_{47}, b_{52}, b_{63}$ ), que filhos e amigos sejam avisados e acompanhados de perto (b15, b25, b35, b48) e que todos digam não às drogas (f23, b23).

Os maiores alvos individuais das fake news foram políticos, artistas, atletas e famosos ou seus familiares. Neste caso, parece haver clara intenção de prejudicar a imagem de uma pessoa pública. Em menor quantidade, determinados grupos sociais também foram alvos, como casais homoafetivos e pessoas jovens. Para as agências, as fake news analisadas trazem com frequência ilustrações e legendas que não confirmam seu conteúdo. Segundo os artigos de checagem, os acusados seriam não apenas vítimas de fake news, mas "vítimas da web". Afinal, a falsa publicação é legitimada pelo compartilhamento acrítico.

Em uníssono, as agências de checagem sugerem em geral que o leitor fique atento e se informe. Ressalta-se, porém, que as checagens também possuem diferentes interpretações. Os comentários que acompanham o desmascaramento das notícias falsas, realizados no $\varepsilon$-farsas.com, propõem a abstinência e uma ação vigilante e preventiva. Ao comentar a fake new em fi7, essa agência sugere que "nunca é demais ficar de olho nos filhos". Em f3o, conclui: "NÃO USEM DROGAS". Já Boatos.org parece ter uma perspectiva mais próxima da redução de danos, vide bi6, quando a agência afirma que "as discussões sobre a legalização das drogas no Brasil ainda engatinham". Em b17, advoga que "mais do que um problema policial, a questão do uso de crack no Brasil é de saúde pública". Ela recomenda "se beber, não dirija" (b46), e reforça que desmentir fake news "não é desculpa para você exagerar no álcool” (b47), por fim observa que o leitor deve cuidar dos filhos sim, "mas não precisa ficar tão paranoico" (b52).

Por fim, as fake news foram reunidas em três unidades de discurso que se mostraram centrais: sátira sobre drogas com potencial para enganar; drogado como categoria de acusação; e epidemia das drogas ilícitas.

Quase metade das notícias falsas (47\%) utilizou humor para satirizar situações que envolvem o uso de substâncias. Essas notícias podem não pretender fazer mal, mas têm potencial para enganar. Entre elas, 31,7\% denunciam indivíduos ou grupos sociais por desvios de conduta, explicados pelo uso de drogas. E 21,1\% divulgam informações sobre drogas ilícitas com conteúdos enganosos e/ou contextos falsos, reproduzindo uma ideia de urgência, pânico ou epidemia.

\section{Discussão}

A partir do que Löwy (2013) denominou como "sociologia crítica do conhecimento", a razão deve remeter à capacidade de distinguir o verdadeiro e o falso. Com a pós-verdade, aprofunda-se um irracionalismo que nega a possibilidade de conhecimento do real, exacerbando o momento subjetivista do processo de conhecimento (Coutinho, 2010) e abrindo amplas possibilidades para que crenças pessoais venham a negar o conhecimento científico.

Este mesmo movimento pode ser identificado em correntes do chamado pensamento pós-moderno. Embora não se possa identificar homogeneidade entre os diversos autores que reivindicam o pensamento pós-moderno no campo das ciências 
sociais, para Netto (2010), alguns elementos comuns permitem caracterizar este pensamento: aceitação da imediaticidade para o conhecimento da realidade, dissolvendo a distinção entre aparência e essência; supressão da diferença entre conhecimento científico e não científico; recusa da categoria de totalidade; privilégio da dimensão simbólica da realidade, reduzindo-a a pura discursividade.

A aproximação entre fake news, pós-verdade e pensamento pós-moderno, pode ampliar a análise do fenômeno fake news, desvelando aspectos que o vinculam às modificações no campo da sociologia do conhecimento e da base material do capitalismo tardio que as sustentam. A verdade, como apontou Gramsci (2007), é ligada a determinadas relações hegemônicas, mostrando sua força e realidade imediatamente no plano da política. Não por acaso, esse campo se presta muito bem a disseminação de falsas notícias como estratégia de luta, reduzindo-a a uma disputa de "narrativas", na qual a relação com a materialidade se perde.

Para além do campo político, as fake news afetam sobremaneira o campo acadêmico-científico, colocando em xeque questões até pouco tempo consensuais. No campo das drogas, constata-se a amplificação de falsas notícias, com distorções que geram os estigmas referentes a essas substâncias e seus usuários, bem como a guerra às drogas (Hari, 2018).

As fake news identificadas nesta pesquisa apresentam conteúdos distorcidos, por exemplo, sobre os efeitos das substâncias, as relações de causa e efeito e sua associação direta com a criminalidade.

Dados do Relatório Mundial sobre Drogas apontam que 35 milhões de pessoas em todo o mundo sofrem com algum transtorno relacionado ao uso de substâncias (UNODC, 2019), e o uso problemático é reiterado em dinâmicas sociais geradas por um sistema que necessita da desigualdade (Arruda et al., 2017). É possível concluir, de acordo com Velho (2008), que o drogado, enquanto personificação de um estigma social, é acusado pela sociedade por problemas que ela mesma gerou, os quais não quer ou não consegue resolver.

A categoria de acusação drogado foi acionada por $31,7 \%$ das notícias falsas. De forma implícita ou explícita, esses sujeitos são apontados como moralmente nocivos, pois têm hábitos e costumes desviantes. Drogados foram apresentados como viciados e/ou doentes, compondo uma representação que mobiliza compaixão e desprezo. Para Velho (2008), essa é uma acusação moral que contamina toda a vida do acusado, estigmatizando-o de forma definitiva. Neste caso, a acusação tem uma dimensão política e totalizadora, porque a partir do discurso sobre a necessidade de controlar desvios e viciados, constrói-se um discurso sobre a normalidade (Alvarez; Fraga; Campos, 2017).

Informações sobre drogas ilícitas foram compartilhadas com conteúdos enganosos e/ou contextos falsos, reproduzindo uma ideia de urgência, pânico ou epidemia em mais de $\mathbf{2 0} \%$ das fake news identificadas pela pesquisa.

A afirmação de que há uma epidemia de drogas no Brasil surge ao arrepio dos estudos disponíveis que podem subsidiar a análise da realidade. Destacase nesse assunto o levantamento realizado por Bastos et al. (2017), publicizado apenas em 2019, que revela panorama do uso de drogas lícitas e ilícitas no Brasil. Segundo esse levantamento, não existe uma epidemia do uso de drogas no país.

O sentido da falsa epidemia das drogas é ser crise moderna que justifica ações excepcionais. Para Mészáros (2009), a crise é o novo modo de governar. As constantes perturbações, que assumem a forma do terror e de catástrofes apocalípticas, servem para quebrar laços e controlar a população, mantendo uma insegurança existencial crônica. Portanto, o discurso sobre a epidemia das drogas oferece uma distração para a população e, ao mesmo tempo, um motivo para intervenções autoritárias.

Aguerra contra as drogas, presente em perspectivas que apontam a abstinência como única possibilidade para as políticas de saúde, é justificada pelo argumento dessa (falsa) epidemia. Contraditoriamente, tal guerra não é propriamente contra as drogas ilícitas, mas, como quaisquer outras guerras, é contra pessoas. Evidências científicas atuais apontam que a guerra às drogas está falhando (Godlee, 2016, 2017).

Em outro sentido, o movimento de redução de danos contrapõe-se à lógica da guerra às drogas (Moreira et al., 2019), incorporando lutas sociais a fim de instrumentalizar usuários e profissionais para a compreensão das raízes do problema, reforçando o protagonismo para construção de políticas adequadas 
à realidade, que respondam às necessidades de quem usa drogas (Santos; Soares, 2013).

Para Zarzalejos (2017), a divulgação de notícias falsas conduz à banalização da verdade, colocando em xeque o valor ou a credibilidade dos meios de comunicação, que se veem inferiorizados diante das opiniões pessoais.

Entretanto, pelo menos em teoria, essa forma que ridiculariza o cotidiano poderia iluminar desigualdades e injustiças sociais, gerando problematizações e reflexões na atualidade para compor estratégias de comunicação em saúde.

De fato, é um grande desafio fazer comunicação em saúde em uma sociedade que valoriza o relativismo científico e a desconstrução da ideia de verdade. Cavaca et al. (2018) descrevem prioridades potenciais para uma comunicação em saúde, a partir do chamado "valorsaúde", fundamentado em critérios epidemiológicos, e não apenas no chamado "valor-notícia”. Já Henriques (2018) aponta a necessidade de oferecer e divulgar fontes confiáveis para os profissionais e a comunidade, em especial por meio do fortalecimento das instituições e de suas áreas de comunicação.

Essas são reivindicações importantes para fortalecer as políticas de saúde na área de drogas, mas não parecem suficientes para democratizar a comunicação no contexto de uma sociedade proibicionista. Afinal, a comunicação não é unidirecional, senão um direito vocalizado por setores populares e por outros segmentos da sociedade comprometidos ou não com a saúde baseada em evidências científicas.

\section{Considerações finais}

Diante da perda de credibilidade da mídia e da ciência, urge oferecer e divulgar evidências e fontes confiáveis para os profissionais e para a comunidade em geral.

Os sites de checagem de fatos desempenham um papel importantíssimo ao desmentir notícias falsas. Todavia, eles não desconstruirão sozinhos os estigmas sobre drogas, que têm em sua própria gênese a desinformação e distorção de fatos. Assim, as fake news sobre o tema, especialmente aquelas com viés negativo, já contam com uma espécie de predisposição para serem recebidas como verdades.
Estratégias conjuntas que unam o fortalecimento de instituições públicas de pesquisa em saúde, democratização da comunicação e redução de danos poderiam aumentar a capilaridade de ações e pesquisas que respondam as necessidades sociais em saúde.

Como pano de fundo da problematização acerca do fenômeno fake news, é importante questionar concepções que advogam a impossibilidade da compreensão do real, abrindo espaço para que o conhecimento acadêmico-científico seja equiparado a convicções pessoais, reforçando subjetivismos e irracionalismos que tendem a fortalecer a recepção e a proliferação de fake news nos mais variados campos do conhecimento.

Espera-se que as reflexões aqui desenvolvidas inspirem a criação e modificação de estratégias comunicativas para iluminar necessidades, desigualdades e injustiças sociais, gerando problematizações e reflexões na atualidade.

\section{Referências}

ALLCOTT, H.; GENTZKOW, M. Social media and fake news in the 2016 election. Journal of Economic Perspectives, Pittsburgh, v. 31, n. 2, p. 211-36, 2017.

ALVAREZ, M. C.; FRAGA, P. C. P.; CAMPOS, M. S. Apresentação: perspectivas atuais sobre políticas, produção, comércio e uso de drogas. Tempo Social, São Paulo, v. 29, n. 2, p. 1-14, 2017.

ARRUDA, M. S. B. et al. Crackland: beyond crack cocaine. Social Medicine, Nova York, v. 11, n. 1, p. 8-17, 2017.

BAKHTIN, M. M. Estética da criação verbal. 6. ed. São Paulo: Martins Fontes, 2011.

BARATTA, A. Introdução a uma sociologia da droga. In: MESQUITA, F.; BASTOS, F. I. (Org.). Drogas e aids: estratégias e redução de danos. São Paulo: Hucitec, 1994. p. 21-43.

BASTOS, F. I. P. M. et al. (Org.). III levantamento nacional sobre o uso de drogas pela população brasileira. Rio de Janeiro: Fiocruz/ICICT, 2017.

CAVACA, A. G. et al. 'Valor-saúde': critérios epidemiológicos potenciais para a comunicação e saúde. Reciis, Rio de Janeiro, v. 12, n. 1, p. 26-42, 2018. 
CONDE, C. A. G. F. Desinformação: qualidade da informação compartilhada em mídias sociais. 2018. Dissertação (Mestrado em Ciência da Informação) Universidade Estadual de Londrina, Londrina, 2018.

COUTINHO, C. N. O estruturalismo e a miséria da razão. São Paulo: Expressão Popular, 2010.

DERAKHSHAN, H.; WARDLE, C. Information disorder: definitions. In: UNDERSTANDING AND ADDRESSING THE DISINFORMATION ECOSYSTEM, 2017, Philadelphia. Proceedings... Philadelphia: Annenberg School for Communication, 2017. p. 5-12. Disponível em: 〈http://bit.ly/340I9sG $>$. Acesso em: 21 ago. 2019.

'FAKE NEWS' é eleita palavra do ano e ganhará menção em dicionário britânico. BBC Brasil, Londres, 2 nov. 2017. Disponível em: <https://bbc. in/2DjRugd $>$. Acesso em: 18 mar. 2019.

GODLEE, F. The war on drugs has failed: doctors should lead calls for drug policy reform. BMJ, Chicago, v. 355, n. 6067, 2016.

GODLEE, F. Treat addictions with evidence, not ideology. BMJ, Chicago, v. 357, n. 1925, 2017.

GRAMSCI, A. Cadernos do cárcere. 3. ed. Rio de Janeiro: Civilização Brasileira, 2007.

HARI, J. Na fissura: uma história do fracasso no combate às drogas. São Paulo: Companhia das Letras, 2018.

HARSIN, J. Post-truth and critical communication studies. Oxford Research Encyclopedia of Communication, Oxford, 20 dez. 2018. Disponível em: <http://bit.ly/34qHy9S>. Acesso em: 21 ago. 2019.

HENRIQUES, C. M. P. A dupla epidemia: febre amarela e desinformação. Reciis, Rio de Janeiro, v. 12, n. 1, p. 9-13, 2018.

IFLA - INTERNATIONAL FEDERATION OF LIBRARY ASSOCIATIONS. How to spot fake news. Haia, 15 ago. 2019. Disponível em: <http://bit.ly/2XVGFno>. Acesso em: 17 ago. 2019.

JERVELUND, S. S. How social media is transforming the spreading of knowledge: implications for our perceptions concerning vaccinations and migrant health. Scandinavian Journal of Public Health, Thousand Oaks, v. 46, n. 2, p. 167-169, 2018.

LÖWY, M. As aventuras de Karl Marx contra o Barão de Münchhausen: marxismo e positivismo na sociologia do conhecimento. 10. ed. São Paulo: Cortez, 2013.

MARCHA DA MACONHA passa pela av. Paulista e chega à Consolação. G1, São Paulo, 26 abr. 2014. Disponível em: <https://glo.bo/2qOenig>. Acesso em: 17 ago. 2019.

MÉSZÁROS, I. A crise estrutural do capital.

São Paulo: Boitempo, 2009.

MEURER, J. L. Gêneros textuais na análise crítica de Fairclough. In: MEURER, J. L.; MOTTA-ROTH, D. (Ed.). Gêneros: teorias, métodos, debates. São Paulo: Parábola, 2005. p. 81-106.

MOREIRA, C. R. et al. Redução de danos: tendências em disputa nas políticas de saúde. Revista Brasileira de Enfermagem, Brasília, DF, v. 72, p. 326-335, 2019. Suplemento 3 .

NETTO, J. P. Posfácio. In: COUTINHO, C. N. $O$ estruturalismo e a miséria da razão. São Paulo: Expressão Popular, 2010.

PAULA, L. T.; SILVA, T. R. S.; BLANCO, Y. A. Pósverdade e fontes de informação: um estudo sobre fake news. Revista Conhecimento em Ação, Rio de Janeiro, v. 2, n. 1, p. 93-110, 2018.

SANTOS, V. E.; SOARES, C. B. O consumo de substâncias psicoativas na perspectiva da saúde coletiva: uma reflexão sobre valores sociais e fetichismo. Saúde \& Transformação Social, Florianópolis, v. 4, n. 2, p. 38-54, 2013.

SOARES, C. B. Consumo contemporâneo de drogas e juventude: a construção do objeto na perspectiva da saúde coletiva. 2007. Tese (Livre-Docência em Enfermagem) - Universidade de São Paulo, São Paulo, 2007.

UNODC - UNITED NATIONS OFFICE ON DRUGS AND CRIME. World drug report 2019. Viena: United Nations, 2019. 
VELHO, G. Individualismo e cultura: notas para uma antropologia da sociedade contemporânea. 8. ed. Rio de Janeiro: Zahar, 2008.
ZARZALEJOS, J. A. Comunicação, jornalismo e 'fact-checking'. Revista UNO, São Paulo, v. 27, p. 11-13, 2017.

\section{Contribuição dos autores}

Pasquim e Oliveira realizaram as buscas. Soares orientou o trabalho e revisou o manuscrito. Todos os autores analisaram os dados e redigiram o artigo.

Recebido: $23 / 08 / 2019$

Aprovado: 22/11/2019 